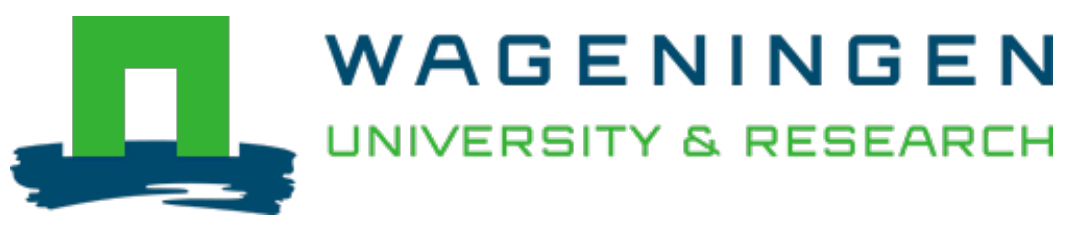

\title{
Understanding the role of institutional intermediaries in the emergence of the circular economy
}

\author{
Circular Economy \\ Fischer, Aglaia; Pascucci, Stefano; Dolfsma, Wilfred \\ https://doi.org/10.4324/9780367816650-8
}

This publication is made publicly available in the institutional repository of Wageningen University and Research, under the terms of article $25 \mathrm{fa}$ of the Dutch Copyright Act, also known as the Amendment Taverne. This has been done with explicit consent by the author.

Article 25 fa states that the author of a short scientific work funded either wholly or partially by Dutch public funds is entitled to make that work publicly available for no consideration following a reasonable period of time after the work was first published, provided that clear reference is made to the source of the first publication of the work.

This publication is distributed under The Association of Universities in the Netherlands (VSNU) 'Article $25 \mathrm{fa}$ implementation' project. In this project research outputs of researchers employed by Dutch Universities that comply with the legal requirements of Article $25 \mathrm{fa}$ of the Dutch Copyright Act are distributed online and free of cost or other barriers in institutional repositories. Research outputs are distributed six months after their first online publication in the original published version and with proper attribution to the source of the original publication.

You are permitted to download and use the publication for personal purposes. All rights remain with the author(s) and / or copyright owner(s) of this work. Any use of the publication or parts of it other than authorised under article $25 \mathrm{fa}$ of the Dutch Copyright act is prohibited. Wageningen University \& Research and the author(s) of this publication shall not be held responsible or liable for any damages resulting from your (re)use of this publication.

For questions regarding the public availability of this publication please contact openscience.library@wur.nl 


\title{
UNDERSTANDING THE ROLE OF INSTITUTIONAL INTERMEDIARIES IN THE EMERGENCE OF THE CIRCULAR ECONOMY
}

\author{
Aglaia Fischer, Stefano Pascucci and Wilfred Dolfsma
}

\subsection{Introduction}

$\mathrm{CE}$ is an emerging framework aiming to tackle 21st century socio-ecological crises (Korhonen et al., 2018; Borrello et al., 2020). Industrial ecology, performance economy, C2C design, complex adaptive system thinking and biomimicry are often identified as the intellectual and conceptual foundations of CE (Webster, 2013; Stahel, 2016; Geissdoerfer et al., 2017; Borrello et al., 2020). It is around the early 2010s that CE has been identified as a context in which novel principles could be 'translated' into business and policy makers practices (Ghisellini et al., 2016; Lieder \& Rashid, 2016). Previously, CE had appeared mostly as a fragmented conceptual framework influencing some regional or national strategies, for example, in China and the EU (European Commission, 2015; Geissdoerfer et al., 2017; Hu et al., 2018). During the last decade, CE has instead emerged as an agenda to scale up environmental practices through 'closed loop strategies', from product and firm level to supply chain and industry level (Ghisellini et al., 2016; Korhonen et al., 2018; Lüdeke-Freund et al., 2019; Borrello et al., 2020). From this perspective, $\mathrm{CE}$ aims at redesigning the global economy and recognizes the need for disruptive changes at an unprecedented scale (Ferasso et al., 2020; Konietzko et al., 2020).

CE entails profound institutional processes to foster socio-economic transitions (Termeer \& Metze, 2019; Flynn \& Hacking, 2019) beyond business strategies and practices (Fischer \& Pascucci, 2017; Schulz et al., 2019). The formation of a novel institutional field, where business activities are possible, is triggered only when formal institutions support informal practices shaping the alignment between business-driven strategies and novel regulatory frameworks (Lawrence et al., 2002; Abbott et al., 2017). For instance, circular business practices, typically embedded in the so-called CBMs (Bocken et al., 2016; Geissdoerfer et al., 2018; LüdekeFreund et al., 2019), need a legal system and a regulatory regime to emerge and 
be established in order to allow these practices to move from niche innovation contexts to a larger societal level (Termeer \& Metze, 2019; Konietzko et al., 2020).

This chapter investigates the process of institutional field formation of CE, by looking at how rulemaking and taking emerge in 'contracts' necessarily for supporting circular business. In this process, we particularly focus on the role of institutional intermediaries and thus use the literature on institutional field formation and the role of institutional intermediaries in that process for theoretical guidance (Hardy \& Maguire, 2017; Zietsma et al., 2017). Conceptualizing CE as a new institutional field particularly expands our knowledge on the role of intermediaries facilitating the institutional change processes supporting CBMs.

The chapter unfolds as follows: Firstly, Section 5.2 sets out how we can understand and experiment with institutions in the CE. Section 5.3 sets forth the methodological design of this chapter. Section 5.4 provides the empirical findings of our case study. Section 5.5 discusses the implications of our findings and theorizes about the relation between circular value proposition elements and institutional settings through institutional intermediary processes.

\subsection{Experimenting with institutions in CE}

Scholars have suggested looking at CE not as the emergence of dispersed business practices or strategies, but as a field of institutional experimentation (Schulz et al., 2019; Borrello et al., 2020). CE currently appears as 'a collection of diverse, interdependent organizations that participate in a common meaning system' (Scott, 2014, p. 106), thus, in our view, forming a nascent institutional field (Zietsma et al., 2017). Following this approach, we investigate how intermediaries have led to the identification and definition of rules and norms, defining key patterns towards the emergence of CE as a novel institutional field. The presence of intermediary organizations, such as network facilitators and policy advocates, is abundantly discussed in the CE empirical literature (Lüdeke-Freund et al., 2019). The EMF, Circle Economy, Metabolic, Accenture, KPMG, the Circular Economy Club, the Cradle to Cradle Products Innovation Institute, amongst many others are reported cases of prominent service and network providers for businesses, policy makers and entrepreneurs engaging with principles and practices of CE (Fischer \& Pascucci, 2017; Lüdeke-Freund et al., 2019). These intermediaries have been able to position themselves between rule makers, like the EU commission, the World Economic Forum and other national or regional governments, and rule takers, such as companies, local communities and citizens. At the same time, they have also lobbied and influenced the definition of public policies and initiatives, for example, to support the experimentation and transition into CE, at both local and global levels (Lüdeke-Freund et al., 2019; Borrello et al., 2020). In our view, their intense and persistent intermediary role has made these organizations as key actors in the definition and formation of $\mathrm{CE}$ as an institutional field. Not without ambiguities (Corvellec et al., 2020), these intermediaries have enacted the role of institutional entrepreneurs, thus orchestrating actions, mobilizing resources and constituencies, 
in order to define a dominant logic and set of practices within the field (Pacheco et al., 2010). The role of intermediary organizations in the field formation and structuration is widely recognized (Purdy \& Gray, 2009; Polzin et al., 2016; Eberhart \& Eesley, 2018). Intermediary practices and logics are adopted by institutional entrepreneurs to facilitate codification, formalization and eventually isomorphism characterizing emerging fields (Hardy \& Maguire, 2017). Extant literature highlights that the role of regulatory intermediaries is particularly critical in the emergence stage of an institutional field, for example, by shaping key relations between 'rule makers' and 'rule takers' (Abbott et al., 2017).

Several intermediaries have emerged in the CE landscape with various functions and roles. As said, the EMF has played a decisive role in framing and positioning the CE in the early 2010s (EMF, 2012; Webster, 2013). Through a series of reports and the set-up of the CE100 network, the EMF has been able to quickly influence the business and regulatory landscape and create a global agenda on CE (EMF, 2015). In parallel, other intermediary organizations have developed networks of collaboration using $\mathrm{CE}$ as a framework to design and implement feasible transformational projects at regional and national levels. Circle Economy, for instance, has developed an extended network of collaborative projects, connecting start-ups, established businesses, municipalities and public agencies operating in different sectors and regions (Bauwens et al., 2020). While all these organizations have had a key role to define principles and practices of $\mathrm{CE}$, so far, limited research has been dedicated to the role of these intermediaries in the making of the CE institutional field. What is particularly missing is a conceptual understanding of how intermediaries have been able to influence the definition of rules, for example, influencing the identification of CE principles, legal structures and policy measures, and their 'translation' into feasible and implementable CBMs.

\subsection{Methodological design}

\subsubsection{Research context}

In line with an inductive focus, this chapter theorizes about the emergence and formation of $\mathrm{CE}$ as institutional field and focuses on the role of institutional intermediaries through a qualitative case study approach. We define an institutional intermediary as any 'actor that acts directly or indirectly in conjunction with a regulator to affect the behaviour of a target' (Abbott et al., 2017, p. 19). The intermediary is a go-between, whose presence necessarily makes some aspects of regulation indirect, as the intermediary stands between the regulator and its target' (Abbott et al., 2017, p. 19). We selected Circle Economy (Circle) as the pivotal case of an institutional intermediary to investigate. Circle, as social enterprise based in Amsterdam (NL), has been one of the most active intermediary organizations since the early 2010s, particularly shaping the relation between 'rule makers' and 'rule takers' in the Netherlands and EU to set a CE agenda. Since its foundation, Circle has focused on 'accelerating practical and scalable implementation of the 
Circular Economy', thus facilitating the establishment and development of a community of practitioners, businesses and institutions (Circle Economy, 2020). Circle has been contributing to the development of several projects and programmes, linking public organizations with businesses and entrepreneurs in all the key sectors of the economy, and particularly in finance, built environment, infrastructure, textile/fashion and waste management sectors (Circle Economy, 2020). Our case study focuses particularly on three strategic projects coordinated by Circle during the last 4 years, namely Fairphone-as-a-Service (FaaS), Building Value (BV), and Coalition Circular Accounting Road-as-a-Service (CCA), spanning from 2017 to 2020 . These projects were all characterized by an interactive format in which a tangible circular business case was the focal point. Workshops and thematic deep dives were organized around certain topics and specific expertise - for instance, from lawyers, taxation experts, financiers and accountants - was invited around the table to discuss opportunities and challenges, professional rules and standards and the need for developing new rules and standards to support CBMs. Thus, the case study - bearing in mind that these projects have been pioneering activities in the CE landscape in the EU - provides a paradigmatic example of the characteristics of intermediary organizations and offers a particular focus on the changes of CE as an emerging institutional landscape over the past 4 years.

\subsubsection{Data collection and analysis}

To carry out the case study informing our theory building from cases approach (Eisenhardt \& Graebner, 2007; Eisenhardt \& Ott, 2017), data were collected from a wide range of documentary data and triangulated with meeting notes and archival information recorded by Circle Economy programme managers (see Table 5.1). More specifically, we have selected and triangulated secondary data derived by published reports and online documents and platforms, with data stemming from internal discussions and processes, thus delving into a rich set of information and sources.

The use of case studies for theory development is appropriate when new phenomena, in this case intermediary processes influencing the emergence and formation of CE as institutional field, have yet to be fully understood and conceptualized (Eisenhardt \& Ott, 2017). Given the nature of inductive research, this study entailed an iterative process from data to theory and purposively selected one case of intermediary organization (Circle Economy) to provide evidence of the conceptual categories emerging from the research questions (Eisenhardt \& Graebner, 2007). The research team focused on three projects in which intermediary activities appeared to be relevant, rich and widely reported, integrating primary and secondary data, and namely: (1) Community of Practice FaaS, (2) Community of Practice BV and the (3) CCA. Thus, an iterative and inductive process of data collection and analysis was undertaken. After collection of reports and meeting notes, the first author coded the contents of the documents for the qualitative analysis. First, all data were summarized, categorized and coded to delineate the different institutional and intermediary processes in the three projects, following a 
TABLE 5.1 Overview of data sources

\begin{tabular}{llc}
\hline Category & Data source & No. of entries \\
\hline Circle Economy Published & & $\mathbf{5 1}$ \\
Reports & & 13 \\
& Business \& Insights Reports & 1 \\
& Brands \& Design Reports & 4 \\
& Built Environment Reports & 11 \\
& Cities \& Regions Reports & 10 \\
& Finance, Legal \& Accounting Reports & 4 \\
& Jobs \& Skills Reports & 8 \\
& Textiles Reports & $\mathbf{4 0}$ \\
Project sessions (transcripts) & & 21 \\
& Community of Practice FaaS & 15 \\
& Community of Practice BV & 4 \\
Project archival files & CCA & $\mathbf{2 8}$ \\
& & 3 \\
& Circular Service Contract iterations & 20 \\
& PowerPoint presentations (internal) & 5 \\
Knowledge Hub documents & PowerPoint presentations (external) & $\mathbf{4 8 9}$ \\
& & 138 \\
& Regulatory and legislative instruments & 162 \\
Total data sources & Economic instruments & 189 \\
\hline
\end{tabular}

Source: Authors.

data-driven categorization. Then, second author followed in the coding process, and through authors' interpretation of emerging patterns from the empirical data, inductively defined suitable theory-driven themes (Eisenhardt \& Graebner, 2007). The entire coding process from first to second round was performed manually and by sharing and categorizing quotes and notes from documents and interviews. At the end of the analytical coding process, we identified and discussed emerging patterns of intermediation in the CE institutional formation process (see Figure 5.1 in Section 5.6).

\subsection{Findings}

In this section, we present the main findings of our analysis. More specifically, in Section 5.4.1, we present how circular value proposition elements (e.g. residual value, time horizon and collaboration) and professional regulatory principles (i.e. contracting, accounting practices and financing considerations), ostensibly at odds with one another, are reconciled to make CE business activities feasible. Based on this evidence and analysis, in Section 5.4.2, we present and discuss findings on the role of the intermediary in the process of rulemaking and taking, and the formation of a regulatory landscape for CE. 


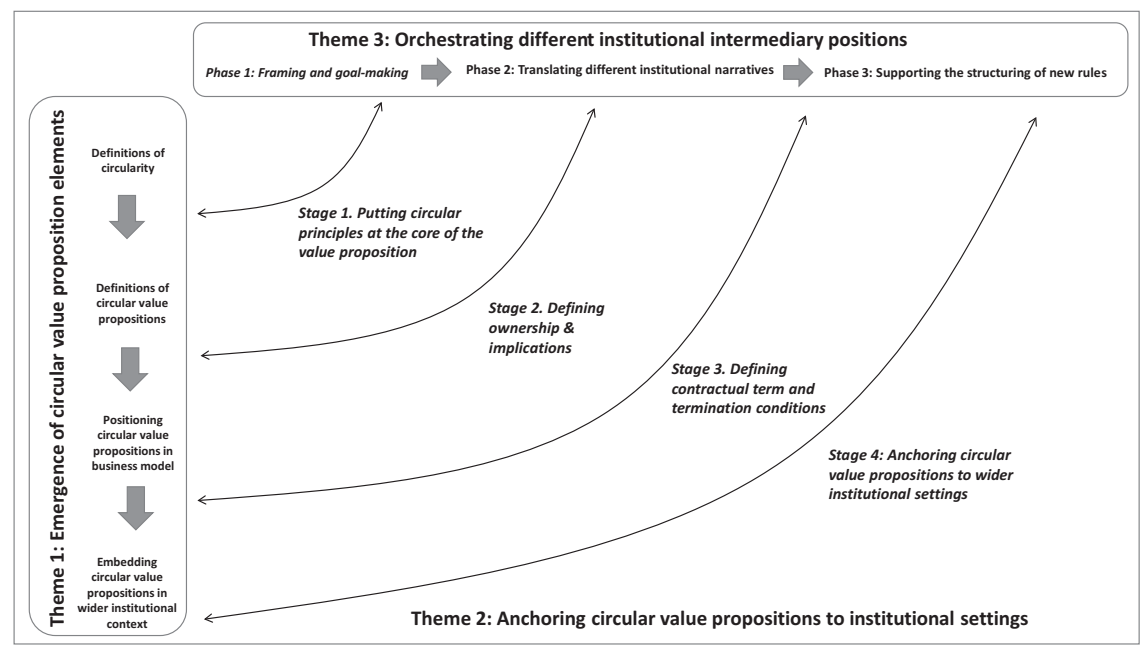

FIGURE 5.1 Patterns of institutional intermediation in the CE institutional formation process

\subsubsection{Co-designing CBMs as institutional process}

\section{Theme 1: Emergence of circular value proposition elements}

In the studied CE projects, there has always been a tension around the understanding of what CE actually is. Even at the end of projects, stakeholders have been rephrasing this or asking again the question of 'what makes this a circular product'. For instance, in the project of CBMs for infrastructural development such as road construction (CCA), an accountant posed this question at the end of the project:

'But how do we define circularity. What is a circular road? When is it circular? If it lasts ten years longer, will it be circular?' . . . 'And what percentage is circular? $100 \%$ circular means that you will pick up that road after forty years, including the sand bed underneath and completely built it up again somewhere else. And then, you are only talking about material. I think that should still be possible' . . 'So no addition of raw materials to put it that way. Is that circular?'

(Controller at road company, CCA)

The question of what is circular was not definitively answered by participants but linked to the emergence of circular value proposition elements. These elements need to be translated into terms that commercial partners could work with. For instance, the topics longevity and cascading activities (i.e. reuse, repair, refurbish, remanufacture and recycle) play a critical role in building circular value propositions. The phrase below shows how the road construction company comprehends reusing asphalt, the top layer of the road. Moreover, the company representative links 
this issue to the concept of economic residual value. In other words, he assumes a certain value at the end of the user life of the road (e.g. longevity vs cascading).

The incentive we built in is the residual value . . We want to be able to throw this asphalt back into the mill after ten years. Then we will create more sustainable asphalt and instead of just the top layer, we will do it all [e.g. the whole road]. The focus becomes different.

(Road company, CCA)

Similarly, in the 'BV' project, parties have been discussing the value propositions entailing a circular building. One point of view is that a building should be made of circular raw materials, that is, materials that can be reused after the user life of the building. Another point of view is to assume the use of elements and materials harvested from neighbouring buildings that are planned to be demolished, as a value proposition to prioritize the reuse of existing materials above using new materials. This existing building stock could inform architects in their new building designs.

These examples reveal the complexities entangled in the definition of value propositions in the formation of a CBM, due to ambiguity of the CE terminology. For instance, there are trade-offs between several options that are determined by assumptions and choices about short-term versus long-term, materials used, collaboration versus dependency. Our cases are all indicating conversations and negotiations about what circularity means and entails in specific circumstances and what choices have to be made to build the circular value proposition for each specific CBM. Therefore, how to 'translate' terms and definitions of key value propositions, such as longevity and cascading, as elements of CBMs seems to be one of the key steps emerging from our analysis.

\section{Theme 2: Anchoring circular value propositions to institutional settings}

The second theme that emerged in our analysis refers to the anchoring of the circular value propositions to institutional settings. Our findings indicate that defining and enforcing rules through contractual agreements have been particularly relevant to develop a CBM. Contracts have evolved over years to enable business activities. In a linear economy approach, contracts take a standard shape using consolidated legal principles. Instead, parties involved in the formation of a CBM often need to develop new template contracts. Template contracts usually are developed over time to balance interests and adhere to important societal values, captured in regulatory and legal frameworks. Commercial projects entailing the development of a CBM also need to adhere to rules and values, but without the availability of underlying regulatory frameworks. Therefore, the definition of 'template contracts' as a new and emerging regulatory framework needs to be co-developed during the formation of CBMs. For instance, during a project to develop a new value proposition for Fairphone, called FaaS, a new contract template was developed. This would entail Fairphone to offer the functionality of smartphone devices to businesses (i.e. 
companies that provide their employees with a work phone). Part of this project was to set up a contractual agreement between Fairphone and its client. The process of moving from a first idea of what this service entails, to a draft 'Service Level Agreement', to the final contract template has shown some pivotal elements to be included in contracts that aim to structure agreements between parties that have circular principles at their core purpose. The contractual design and enforcement process used a pattern of enactments that we can summarize as follows: (1) first, actors put circular principles at the core of the value proposition; (2) then they focused on defining ownership \& implications; (3) then they engaged in the definition of contractual term and termination. Finally, (4) they anchored circular value propositions to wider institutional settings. We present and briefly discuss findings of these four enactments in the following sections.

\section{Stage 1. Putting circular principles at the core of the value proposition}

The process of shaping the contract evolved in several iterative rounds. During the FaaS project, particularly, Circle Economy was facilitating the process of anchoring circular value propositions and core contractual elements for the first time. Part of this exercise was to create a contract template that would be published open source, so it could be used by any businesses interested in Product-as-a-Service value propositions. In order to guide others to use this template, it included notes for the reader to specify the purpose of newly added clauses that would embody the circular aspects of the contract. These clarifications were added after several conversations about the purpose of a circular Product-as-a-Service value proposition. Namely, Product-as-a-Service in itself is not circular, it can be done with an unsustainable product in a rent-based value proposition. Therefore, the interested parties were very keen to clarify their circular intentions through putting them explicitly at the core of the contract template by stating:

1 [. . . the background of the circular service contract (from linear sale to circular service model).

2 [. . . ] the circular objectives that are being pursued with this circular service contract (to ensure the re-use and/or recycling of the respective product at the end of its technical or economic life or that of any of its components and that the responsibility for that re-use and recycling remains with the producer and is not, upon the sale of the product, passed on to the end consumer who is least equipped to know what to do with the product at the end of such technical or economic life and/or to reduce the energy consumption of the respective product over its lifecycle since the producer is best equipped to achieve that).

3 [. . . the background of the parties and their interest in this circular service contract.

These considerations give 'colour' to the contract and can assist with the explanation of the further contractual provisions.

(FaaS, Circular Service Contract Template, final version) 


\section{Stage 2. Defining ownership and implications}

A key element in the design and enforcement of contracts for CBM propositions has been the definition of ownership issues. For example, an essential element for Fairphone was to remain the owner of the smartphone devices. In this way, Fairphone would have full control over its devices and would receive them back after use in order to be reused, refurbished or recycled. In order to ensure circularity and in support of the product-as-a-service concept, consumers should not own the device but pay for the service it provides. Whereas this was not formulated explicitly in earlier iterations of the agreement, the final contract template encompasses the following clause about ownership:

The legal title to the Product(s) shall remain with the Service Provider and shall at no time pass to the Customer.

(FaaS, Circular Service Contract template, final version)

This implies ownership remains with the service provider. Many contracts in similar circular 'Product-as-a-Service' projects contain a differently formulated ownership clause, similar to the established way of formulating lease contracts. These contracts typically contain a clause about potential transfer of ownership when the contract is terminated.

\section{Stage 3. Defining contractual term and termination conditions}

The other aspect emerging from the analysis of template contract definition is the pivotal role of term and termination conditions. During the process of developing the contract template, the contract term has changed from 1 year to an openended contract. Standard contracts, used in 'linear' BMs, necessarily have a fixed term, while CE by definition is supposed to be an ongoing process. Formulating a contract with an 'open end' incentivizes ongoing services and optimal circularity, instead of steering to the end of a contract and therefore the end of the product lifespan. These considerations led to the definition of two alternative contractual termination definitions:

This Agreement shall be effective from the Effective Date and shall be valid for a period of one (1) year, and can be extended for consecutive periods of one (1) year.

(FaaS, Circular Service Contract template, version 1)

as opposed to:

This Contract shall be effective from the date of this Contract and shall be valid for an indefinite period of time.

(FaaS, Circular Service Contract template, final version) 
In an open-ended contract, the service is the focal point. How this service is provided, with what specific asset or combination of assets and activities (e.g. a product and maintenance and repair services), is subordinate to this. However, the backside of this open-ended contract period was that termination was not set at a specific date. Moreover, parties should be able to terminate the contract flexibly:

Each Party shall have the right, without prejudice to its other rights or remedies, to terminate the Contract with immediate effect by giving a $[\lambda]$ days' written notice to the other Party.

(FaaS, Circular Service Contract template, final version)

An additional clause was inserted about termination of the contract, for example, in case the customer would not be satisfied with the services. A provision on termination should be specified in order to cover value at risk in case of termination. Since 'value at risk' directly relates to the possibility to finance aspects of a circular value proposition, such a clause is needed. Without it, a CE project would not be able to get finance.

\section{Step 4: Anchoring circular value propositions to wider institutional settings}

The final step emerging from our analysis refers to the anchoring of circular value propositions to a wider set of institutional elements, going beyond the contractual and inter-organizational level. Particularly, these elements related to accounting and financial issues. From an accounting perspective, a template contract, serving a circular business proposition, implies transfer of risk and reward and therefore resembles a sale. In the Road-as-a-Service project, initially the contract was phrased for the linear economy, resulting in a regular leasing agreement (i.e. sale). This implied that the road company would not remain the owner of the road, hence losing the right of reusing the materials after its use phase, and the incentive to build and maintain the road as sustainably as possible. We report the conversation below as informative of the process just described:

(accountant) stated: The contract is essential. If it becomes clear that the province is likely to take over the road in ten years from now, this implies a 'sale'. You [road company] have a long-term claim on the province that is being paid over a ten-year period. Then you [road company] actually have no road on your balance sheet, and also no raw materials. (CCA)

And, (Accountant): Accounting follows risk and reward and what you agree with each other is very decisive, and this is actually a sales contract.

(Regional government): Yes, that is exactly what I thought. It is just like a lease structure. You just get a kind of maintenance costs that you then settle on a monthly basis. So in that sense you are getting close to the way it is now.

(Road company): Yes, they actually just postpone that [sale] for 30 years. That is then all you achieve. 
(Accountant): But should we take this as a starting point or should we say 'no, the idea was to have it on the road company balance sheet?'

(Accountant): The advice is actually to try to build the contract up in such a way that it will be a rental contract. (CCA)

Tensions can also arise in new ownership structures when agreements involve more than two parties, and risks and rewards are shared in new ways. We report the following key conversation to support this finding:

(Banker): If you look at it from a financing perspective, then I look at the contracts, which parties are involved, where lies the ownership, how is it shifting, and how are cash flows generated? This involves several parties and multiple ownership options and thus also multiple benefit trackers and therefore multiple cash flows. So your point is quite right to try and understand what the risks and rewards are and whether they are distributed evenly between several parties.

(Accountant): And I find those risks and rewards in particular crucial for reporting. Do you see it in the financial statements?

(Banker): I also understand that it is sometimes very opaque because current standards do not assume multiparty agreements.

(Accountant): And maybe those risks and rewards are shared.

(Banker): In fact, I think from a circular perspective that is precisely the incentive.

(Accountant): That is actually . . . indeed you say that belongs to . . . [circular economy], but that does not fit into the . . . [current reporting standards] - it is either one or the other, and you ultimately determine the report. It is very interesting, that risk and reward issue is essential. (CCA)

From a financial perspective, this is complex and difficult to accommodate. However, bankers stated that this sharing of risks and rewards is an important incentive in a CBM. Therefore, bankers have to broaden their perspective in order to reinterpret risks and rewards in CBMs that are characterized by long-term collaboration and interdependence of companies. This entails the emergence and definition of new rules at sectoral level, able to regulate risk and reward across clients and circular business projects.

\subsubsection{Orchestrating different institutional intermediary positions}

In the previous section, circular value propositions have been connected to institutional mechanisms that translate these propositions into contracts and rules for defining ownership and for allocating risks and rewards, in order to make these projects attractive for financiers and investors. This is not a straightforward process since many iterative steps are made between and across value proposition elements, and legal and regulatory principles. This iterative process is key for the rulemaking and taking, and it is the outcome of the orchestrating actions of Circle as intermediary organization (Theme 3: Orchestrating different institutional intermediary positions). Thus, in the following section, the role of the intermediary activities in this process 
is further elaborated. An institutional intermediary organization will be orchestrating three kinds of sequential activities, namely: framing and goal-making, followed by translating, and finally, structuring.

\section{Theme 3: Orchestrating different institutional intermediary positions}

\section{Phase 1: Framing and goal-making}

To begin with, the institutional intermediary needs to make sure that a common purpose is defined in a circular business project. All parties need to understand that a CE goal is pursued, and that pursuing such a goal requires new thinking and clear definitions/terminology. Keeping stakeholders with different professional backgrounds involved and on the same page demands a constant reframing and translating of the goal and means at hand.

So it is also a bit of definitions, agreement on what we are actually talking about and clarity in what we are doing.

(Project Manager Circle Economy, CCA)

The different options need to be spelled out, including their consequences for the parties involved and for the common objective of delivering a circular project. Specifically, the core value proposition elements (reusing elements versus new CE elements) and commercial structuring elements (e.g. between CE value proposition elements and contracting, and ultimately financial viability) need to be jointly framed and clearly phrased. We have defined framing and goal-making the process of sensing and checking with stakeholders their understanding, buying in and finetuning of a common purpose in the definition of the circular value propositions.

\section{Phase 2: Translating different institutional narratives}

Once the first step of framing collective has resulted in reaching a common aim, the next step entails that the different players agree on how to devise a contract template. However, they 'speak' different institutional narratives, since many are involved in ongoing commercial activities that are shaped by linear economy regulatory regimes. Producing something in the linear economy involves delivering it to the customer, and at that moment, transferring future responsibilities (liabilities) as well. This is not just about a mindset, but it has consequences for financing a project, about how to account for costs, revenues and risks. These aspects need to be reflected in contracts underlying a project. For instance, when a road construction company maintains ownership of a road, rather than selling it to the regional government, it charges a rent to the government. In such circumstances, it needs to be clear who takes which risks. Under linear economy assumptions, the owner bares (most of) the risks, but for the road construction company this may be 
unbearable. In addition, if the road construction company maintains ownership, the assets mentioned on its balance sheet will expand substantially, with consequences for how it may operate as a commercial player, and the pace (and magnitude) of the income stream will change too. In terms of the latter, it matters greatly if a firm is dependent on irregular one-off payments as income, or on a dependent stream of rent-income. Higher predictability of income streams come at the risk of greater challenges in the future, however. More assets on the balance sheet leaves the firm vulnerable to fluctuations in the value of these assets. On the other side, owning a future stock of resources and guaranteeing a stable cash flow have spurred interest of many parties to create these new (circular) BMs. The following phrase shows an accountant's perspective on why this is an attractive idea and what the difference between a sale and a service model entails:

(Accountant): The main issue is a sale or not? When there is a sale, the road goes to the province and on its balance sheet. Then the road company starts collecting money for the sale. This can be all at once or it can be in instalments. But that's really just paying off a long-term receivable from the sale. Risk and reward have been transferred to the province. That has actually always been the usual practice. But this coalition actually wants to work on Road-as-a-Service, whereby the road company remains the owner of the road, which also remains as a fixed asset on the road company's balance sheet. The province will pay for the use, it is really just rental. And then a very relevant question arises about risk and reward, since the province can say 'I stop the renting'. (CCA)

Translating institutional narratives is therefore the process of moving back and forth between circular value proposition elements and regulatory principles, and how actors from different backgrounds interpret them, adjusting them to one another. When successful, the result is a common language and understanding that creates the space for a shared institutional narrative.

\section{Phase 3: Supporting the structuring of new rules}

As discussed previously, a crucial aspect of CBMs is to understand how to spread risks and rewards over time. Moreover, decision-making for CBMs demands banks and financial institutions to rethink some long-established assumptions and practices. The following conversation between bankers and Circle shows how financial rules can be used for ongoing circular contracts. The underlying business cases entail an asset component (for instance a road) with which a cash flow is generated (payment of the service fee). This kind of value proposition demands a fundamentally new interpretation of the financial statements and balance sheet. Moreover, it demands new forms of interaction between different departments of the bank, namely corporate finance and project finance:

(Road company): it is not that important for the project financing, but at a certain point from the corporate finance perspective they say 'wait, your solvency is going to be very low, all of which consists of receivables'. 
(Project Manager Circle economy): And how should I envision that in a bank?

(Banker A): You mean who is in charge of the two [i.e. project finance versus corporate finance]?

(Project Manager Circle economy): Yes exactly. And do they correspond or not?

(Banker A): Yes absolutely. But who's in charge, it depends

(Banker B): Yes in principle, they are two separate parts, so they both look at their own financing and their own merits and of course you talk to each other. But they are not going to coordinate with each other: 'hey can you do a bit more debt, then I do a bit less'. So in principle it must for both processes simply fit within the project financing policy metrics, and within the corporate financing policy.

(Project Manager Circle economy): Ok, but I'm not very familiar with how these kinds of processes go in a bank, so I'm curious. Do you have a financing request and there is a bit of corporate finance and a bit of project finance, or how does that work?

(Banker A): No

(Project Manager Circle economy): Those are very different types of applications?

(Banker B): Well on the risk side it all comes down to one. And there has to be a decision. It is somewhat dependent on the amounts. In the end it can coincide with corporate risk or with central risk and then it becomes interesting because then, what are we going to emphasize? (CCA)

In this conversation, the intermediary asks bankers about project finance (nonrecourse debt) and corporate finance. Since this circular proposition entails an asset with which cash flows are generated, it would fit in a project finance structure. However, keeping ownership of the roads implies a growing balance sheet of the road company. From a corporate finance perspective, this may be problematic, since some financial ratios by which a bank is rated will no longer comply with a business-as-usual balance sheet from a company that sells products instead of holding on to them and providing services through their customers using them. The intermediary asks the bankers whether these two departments in the bank correspond with one another. This is the case, but they do not coordinate and make their own separate decisions - each being held responsible for their own bottom line. This is an interesting finding, since growing balance sheets - that is, the financial consequence of Product-as-a-Service BMs - will likely be a common issue in CBMs. What the bankers here express provides an indication of how CBMs will be able to expand in the near future: offering low-risk, reliable-income investment opportunities first. Moreover, the clean-cut divide between corporate finance and project finance may impede effective financing of these BMs. This means financiers have to shift their perspective by translating this narrative into a new institutional structure.

(Banker) Look, I think - and that is progressive for banks to think that way, I have to saythat the crux is in those stimulants towards a circular economy. And then ownership legal and economic ownership - is going to have a different impact. And that makes it very difficult when I am talking to my constituencies. . . because they only look at those things from a certain framework and then you simplify everything, and you do not manage to open up to change. And I think it is very important for banks to keep an open vision and to fully understand what that [circular] stimulus serves. (CCA) 
These findings indicate that definition of circular value propositions not only need novel contractual elements to be devised between involved parties, but they also shape new regulatory principles. We define this last activity of the intermediary process as supporting the structuring of new rules.

\subsection{Discussion}

Building on extant literature on CBMs and by adopting the perspective of regulatory and institutional intermediary studies, we have been able to analyse the definition and development of value propositions in CBMs as a key institutional process. While existing literature mostly focuses on the taxonomy, categorization or the role of enablers and barriers in the emergence of CBMs (Bocken et al., 2014; Geissdoerfer et al., 2017; Geissdoerfer et al., 2018), we have used CBMs as a context in which meaningful institutional and regulatory processes are taking place. What our analysis highlights is an order characterizing the process of identification and formation of an institutional landscape in the CE (see Figure 5.1). In the void of (general) regulatory frameworks, rules and contractual norms, CBMs function as 'islands of rules'. Organizations participating in projects aiming at implementing CE principles have to define and shape the elements of BMs in this void, often through the key role of an intermediary organization. In these projects, the identification and definition of the value proposition elements is the first step in the institutional formation process (Theme 1: Emergence of circular value proposition elements). Moreover, while discussing the building blocks of BMs, all parties are involved in intense interactions in order to make sense of their role and to adopt common terminology that will be translated in propositions and contractual norms (Theme 2: Anchoring circular value propositions to institutional settings). Extant literature has already stressed the relevance of framing carefully the concept of CE (Webster, 2013) and highlighted the presence of ambiguities in its definitions (Kirchherr et al., 2017; Corvellec et al., 2020). However, this critique has mostly addressed the need for clarity of definitions from a conceptual or academic standpoint (Morseletto, 2020). Our findings also show that ambiguities in the terminology have a role in the process of definition of the building blocks of CBMs, and even more importantly, they shape the institutional and regulatory formation processes. 'What is circular in this project' is therefore not only an issue of identity or positioning of an organization in the CE landscape, but a fundamental problem in the operationalization of its activities. The definition of a commonly understood terminology is the foundational step to define contractual frameworks, and particularly to adopt a contract template that can be used by all parties in a project and adapted as the BM elements are forged.

Our analysis has revealed that this institutional process is in reality mixed, ambiguous and complex. The role of the intermediary is pivotal (Theme 3: Orchestrating different institutional intermediary positions) to create an approach that enables disentangling different frames and topics, providing clarity and an overview to the parties involved, often with different backgrounds and interests. Finally, we have identified the need for intermediaries for shaping and codification of new 
professional and business regulatory principles. All these orchestrating activities are important and have their own challenges. However, translating seems to be the key essential activity that sets a successful intermediary process. Since this is the needed translation of ideas and concepts into contractual rules and elements. The mutual understanding between the company developing circular value propositions, and the partners and service providers is essential to hook their perspectives into each other. When this intermediation is not happening, the results are 'linear business with a circular touch' as we see often when looking into contracts that do not resemble circularity as intended by the business, or financial structures like lease, that are often used but are not fit for circularity.

Looking at our findings from a broader theoretical perspective, what has emerged follows quite closely the four steps of institutional field formation as identified in literature (Zietsma et al., 2017). First, organizations (e.g. Circle Economy, Fairphone and building contractors) claiming to engage and practice similar principles (e.g. circular activities and value propositions) increasingly interact and form collaborative networks progressively setting boundaries. Second, while these interactions are widespread and predominantly collaborative, some networks become progressively more influential and somehow more dominant than others, indicating the presence of competing coalitions and hierarchical relations between actors (e.g. between partners in the analysed projects and between projects). Third, other complementary and somehow competing sets of knowledge and information emerge, adding to the frames informing actors operating in the field (e.g. consultants, experts and other companies operating in other sectors, such as banking, legal firms and accounting). This has also implied the emergence of a diverse set of shared principles and practices between actors and networks of actors. Finally, despite the increased competition between actors in the field, we observe the joint effort to define a common identity, for instance, looking at core values and worldviews (Davis \& Marquis, 2005; Zietsma et al., 2017).

\subsection{Conclusions}

Our study supports a novel conceptualization of the role and functions of intermediaries in the institutional formation of rules supporting circular value propositions. This is crucial to understand how the transition into CE may look like in the years to come. On the one hand, some institutional intermediaries like Circle Economy, have been able to position themselves in between rule makers and rule takers, such as companies, local communities and citizens. On the other hand, the same institutional intermediaries have been acting as rule makers, for example, by codifying business practices into industry standards (e.g. rules in contracts, BMs and interfirm collaborations), subsequently used by public authorities as template and best practices to formalize rulemaking processes (Fischer \& Pascucci, 2017). Sometimes, intermediaries have been identified directly by rule makers as 'arm-length organizations' to experiment new standards, supply chain and contractual arrangements, ownership and property right regimes (Domenech \& Bahn-Walkowiak, 2019). 
Based on our findings, the formation of CE as a novel institutional field seems highly dependent on how rulemaking and taking processes to support CBMs will be able to anchor with existing regulatory frameworks. While these processes have been mostly defined through the interaction of private and public actors, the definition of a common set of rules is still lacking (Schulz et al., 2019). For instance, clear definitions of what is considered a 'circular practice', or the creation of industry standards, the definition of inter-organizational bodies to represent the interest of 'circular businesses', and more in general an agreed set of regulatory instances defining, supporting and limiting the organizational boundaries of actors operating in the CE domain, have not emerged fully (Flynn \& Hacking, 2019). Instead, rulemaking and taking in the CE seem still characterized by a high level of ambiguity and complexity (Corvellec et al., 2020; Cainelli et al., 2020). As highlighted by Scott (2014), this might indicate the still nascent nature of CE as institutional field, where processes of organizational standardization and homologation, something we can define as isomorphic pressures (DiMaggio \& Powell, 1983), are still in the making. As an emergent institutional field, CE is influenced by multiple dynamics: on the one hand, $\mathrm{CE}$ is driven by practitioners introducing new regulations and norms at business and supply chain level in institutional voids (Fischer \& Pascucci, 2017). At the same time, CE is driven by large public and private organizations introducing regulations and norms at industry, region or country level (Lieder \& Rashid, 2016; Hu et al., 2018). In both contexts, rulemaking and taking processes, the role of institutional intermediaries, organizations operating in between institutional levels or contexts, seem to be key in the emergence of CE as a novel institutional field.

\section{References}

Abbott, K. W., Levi-Faur, D., \& Snidal, D. (2017). Theorizing regulatory intermediaries: The RIT model. The Annals of the American Academy of Political and Social Science, 670(1), $14-35$.

Bauwens, T. J. F., Mees, R., Gerards, M., Van Dune, J., Friedl, H., Von Daniels, C., \& Kirchherr, J. W. (2020). Disruptors: How circular start-ups can accelerate the circular economy transition. Retrieved April 27, 2020, from file:///C:/Users/sp587/Downloads/DIS RUPTORS_CIRCULAR_START_UPS_UU_E_VERSION.pdf

Bocken, N. M., De Pauw, I., Bakker, C., \& van der Grinten, B. (2016). Product design and business model strategies for a circular economy. Journal of Industrial and Production Engineering, 33(5), 308-320.

Bocken, N. M., Short, S. W., Rana, P., \& Evans, S. (2014). A literature and practice review to develop sustainable business model archetypes. Journal of Cleaner Production, 65, 42-56.

Borrello, M., Pascucci, S., \& Cembalo, L. (2020). Three propositions to unify circular economy research: A review. Sustainability, 12(10), 4069.

Cainelli, G., D'Amato, A., \& Mazzanti, M. (2020). Resource efficient eco-innovations for a circular economy: Evidence from EU firms. Research Policy, 49(1), 103827.

Circle Economy. (2020). Knowledge-Hub inventory. Retrieved April 27, 2020, from https:// circle-lab.com/knowledge-hub 
Corvellec, H., Böhm, S., Stowell, A., \& Valenzuela, F. (2020). Introduction to the special issue on the contested realities of the circular economy. Culture and Organization, 26(2), 97-102.

Davis, G. F., \& Marquis, C. (2005). Prospects for organization theory in the early twentyfirst century: Institutional fields and mechanisms. Organization Science, 16(4), 332-343.

DiMaggio, P. J., \& Powell, W. W. (1983). The iron cage revisited: Institutional isomorphism and collective rationality in organizational fields. American Sociological Review, 147-160.

Domenech, T., \& Bahn-Walkowiak, B. (2019). Transition towards a resource efficient circular economy in Europe: Policy lessons from the EU and the member states. Ecological Econonomics, 155, 7-19.

Eberhart, R. N., \& Eesley, C. E. (2018). The dark side of institutional intermediaries: Junior stock exchanges and entrepreneurship. Strategic Management Journal, 39(10), 2643-2665.

Eisenhardt, K. M., \& Graebner, M. E. (2007). Theory building from cases: Opportunities and challenges. Academy of Management Journal, 50(1), 25-32.

Eisenhardt, K. M., \& Ott, T. E. (2017). Rigor in theory building from multiple cases. In The Routledge companion to qualitative research in organization studies (pp. 79-91). Routledge.

EMF (Ellen MacArthur Foundation). (2012). Towards the circular economy, report Vol. 1 Economic and business rationale for an accelerated transition. Ellen MacArthur Foundation.

EMF (Ellen MacArthur Foundation). (2015). Growth within: A circular economy vision for a competitive Europe. Ellen MacArthur Foundation.

European Commission. (2015). Closing the loop - An EU action plan for the circular economy. Communication From the Commission to the European Parliament, the Council, the European Economic and Social Committee and the Committee of the Regions No. COM(2015) 614/2). European Commission.

Ferasso, M., Beliaeva, T., Kraus, S., Clauss, T., \& Ribeiro-Soriano, D. (2020). Circular economy business models: The state of research and avenues ahead. Business Strategy and the Environment, 29(8), 3006-3024.

Fischer, A., \& Pascucci, S. (2017). Institutional incentives in circular economy transition: The case of material use in the Dutch textile industry. Journal of Cleaner Production, 155, 17-32.

Flynn, A., \& Hacking, N. (2019). Setting standards for a circular economy: A challenge too far for neoliberal environmental governance? Journal of Cleaner Production, 212, $1256-1267$.

Geissdoerfer, M., Morioka, S. N., de Carvalho, M. M., \& Evans, S. (2018). Business models and supply chains for the circular economy. Journal of Cleaner Production, 190, 712-721.

Geissdoerfer, M., Savaget, P., Bocken, N. M., \& Hultink, E. J. (2017). The circular economy - A new sustainability paradigm? Journal of Cleaner Production, 143, 757-768.

Ghisellini, P., Cialani, C., \& Ulgiati, S. (2016). A review on circular economy: The expected transition to a balanced interplay of environmental and economic systems. Journal of Cleaner Production, 114, 11-32.

Hardy, C., \& Maguire, S. (2017). Institutional entrepreneurship and change in fields. In The Sage handbook of organizational institutionalism (pp. 261-280). SAGE Publications LTD.

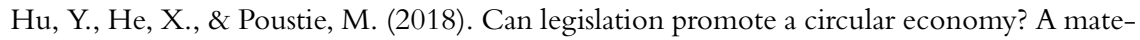
rial flow-based evaluation of the circular degree of the Chinese economy. Sustainability, 10(4), 990.

Kirchherr, J., Reike, D., \& Hekkert, M. (2017). Conceptualizing the circular economy: An analysis of 114 definitions. Resources, Conservation \& Recycling, 127, 221-232.

Konietzko, J., Bocken, N., \& Hultink, E. J. (2020). Circular ecosystem innovation: An initial set of principles. Journal of Cleaner Production, 253, 119942.

Korhonen, J., Nuur, C., Feldmann, A., \& Birkie, S. E. (2018). Circular economy as an essentially contested concept. Journal of Cleaner Production, 175, 544-552. 
Lawrence, T. B., Hardy, C., \& Phillips, N. (2002). Institutional effects of interorganizational collaboration: The emergence of proto-institutions. Academy of Management Journal, 45(1), 281-290.

Lieder, M., \& Rashid, A. (2016). Towards circular economy implementation: A comprehensive review in context of manufacturing industry. Journal of Cleaner Production, 115, $36-51$.

Lüdeke-Freund, F., Gold, S., \& Bocken, N. M. (2019). A review and typology of circular economy business model patterns. Journal of Industrial Ecology, 23(1), 36-61.

Morseletto, P. (2020). Targets for a circular economy. Resources, Conservation \& Recycling, 153, 104553.

Pacheco, D. F., York, J. G., Dean, T. J., \& Sarasvathy, S. D. (2010). The coevolution of institutional entrepreneurship: A tale of two theories. Journal of Management, 36(4), 974-1010.

Polzin, F., von Flotow, P., \& Klerkx, L. (2016). Addressing barriers to eco-innovation: Exploring the finance mobilisation functions of institutional innovation intermediaries. Technological Forecasting and Social Change, 103, 34-46.

Purdy, J. M., \& Gray, B. (2009). Conflicting logics, mechanisms of diffusion, and multilevel dynamics in emerging institutional fields. Academy of Management Journal, 52(2), 355-380.

Schulz, C., Hjaltadóttir, R. E., \& Hild, P. (2019). Practising circles: Studying institutional change and circular economy practices. Journal of Cleaner Production, 237, 117749.

Scott, W. R. (2014). Institutions and organizations (4th ed.). Sage.

Stahel, W. R. (2016). The circular economy. Nature, 531(7595), 435-438.

Termeer, C. J. A. M., \& Metze, T. A. P. (2019). More than peanuts: Transformation towards a circular economy through a small-wins governance framework. Journal of Cleaner Production, 240, 118272.

Webster, K. (2013). What might we say about a circular economy? Some temptations to avoid if possible. World Futures, 69(7-8), 542-554.

Zietsma, C., Groenewegen, P., Logue, D. M., \& Hinings, C. R. (2017). Field or fields? Building the scaffolding for cumulation of research on institutional fields. Academy of Management Annals, 11(1), 391-450. 